\title{
The obscure impact of Nipah virus
}

Anupam Saha ${ }^{1}$, Biplab Debnath ${ }^{2}$

DOI. $10.21931 / \mathrm{RB} / 2019.04 .01 .13$

Abstract: The motivation behind this introduction is to feature the known and deep impact subjected to the Nipah Virus (NiV). Principally concentrating on preventive measures and the treatment of the Nipah Virus. NiV is an individual from the family Paramyxoviridae, class Henipavirus. NiV was at first recognized in 1999, amid a flare-up of Encephalitis and respiratory sickness among pig ranchers and individuals with close contact with pigs in Malaysia and Singapore. Nipah infection caused a generally gentle ailment in pigs, yet almost 300 human cases with more than 100 passings were accounted for in 1999. Not just in Malaysia its spread around the world. A case-controlled survey ponder is directed to decide word related hazard factors for disease. Contact with live pigs, earmarks of being the essential hazard factor for human Nipah infection disease. Coordinate contact with life, possibly contaminated pigs ought to be limited to forestall transmission of this conceivably lethal ZOONOSIS to people. Understanding the significance and in light of specific records, it is an endeavor to assemble it to diagram the qualities and to be worried about this issue. This essential survey is gone for giving a knowledge into this fatal flare-up and to bring it into concern.

Keywords: Zoonosis, Transmission, Nipah Infection, Preventive Measures, Obscure Impact, Treatment and Review.

\section{Introduction}

Nipah infection is another paramyxovirus known to contaminate pigs, canines, people, and, perhaps, bats. By 27 April 1999, the Malaysian Ministry of Health had reports of $257 \mathrm{fe}-$ brile encephalitis cases, including 100 passing's. The lion's share of cases had lab proof of Nipah infection contamination and most happened in the territory of Negeri Sembilan. Pigs were involved as the essential wellspring of human contamination. Most cases had guide presentation to pigs, and viral separates got from pigs and people had the same nucleotide sequences. ${ }^{1}$ It is an outstanding issue worldwide and has influenced India too. This case-controlled diagram examines composed to pick word related hazard factors for infirmity which is caused by the Nipah Virus. Contact with live pigs are stores of being the most significant risk factor for human Nipah pollution ailment. Encourage contact with life, conceivably sullied pigs ought to be compelled to block transmission of this perhaps savage ZOONOSIS to people. Understanding the vitality and in light of specific records, it is an endeavor to gather it to outline the qualities and to be worried over this issue. Malady with $\mathrm{Ni}$ pah contamination is connected with encephalitis (irritation of the cerebrum). After the introduction and an incubating time of 5 to 14 days, illness presents with 3-14 long stretches of fever and cerebral agony, trailed by sluggishness, bewilderment and mental confusion. These signs and signs can progress to daze like state inside 24-48 hours. A couple of patients have a respiratory infection amid the early bit of their defilements, and half of the patients giving extraordinary neurological proposals gave pneumonic insights furthermore. During the Nipah disease affliction scene in 1998-99, 265 patients were sullied with the contamination. Around $40 \%$ of those patients who entered recuperating focuses on certifiable uneasy illness passed on from the ailment. Whole deal sequelae following Nipah disease defilement have been noted, including tireless fits and personality changes. Inactive maladies with coming about reactivation of Nipah disease and death have similarly been represented months and even quite a while after introduction. The ascent of NiV into the pig people and in this way into the human masses is acknowledged to be a result of changes in normal conditions. Urbanization, deforestation, and drought realizing an insufficiency of advantages for bat masses could have compelled bats to move from their essential living spaces to rural districts. Among the components that add to the ailment ascend in Malaysia is the establishment of pig develops inside the extent of the standard host that provoked the basic introduction into the pig people. The upkeep of high densities of pigs incited the brisk dispersal of the sullying inside close-by pig masses, and the vehicle of pigs to other geographic regions for business provoked the quick spread of infirmity in pigs in southern Malaysia and Singapore. This critical examination is a way to give data into this dangerous emit and to bring it into concern. The proximity of high thickness, opening up have people empowered transmission of the disease to human.

Figure 1. Nipah virus disease is an emerging infectious disease spread by secretions of infected bats. It can spread to humans through contaminated fruit, infected animals, or through close contact with infected humans. Nipah virus infection, newly emerging zoonotic infection with acute respiratory syndrome and severe encephalitis. (

${ }^{1}$ M.Pharm, Pharmacology, NSHM College OF Pharmaceutical Technology, NSHM Knowledge Campus, Tollygunge, Kolkata - 700053, WB.

${ }^{2}$ Associate Professor, Department of Pharmaceutical Chemistry, Bharat Technology, Uluberia, Howrah - 711316, WB, INDIA. 


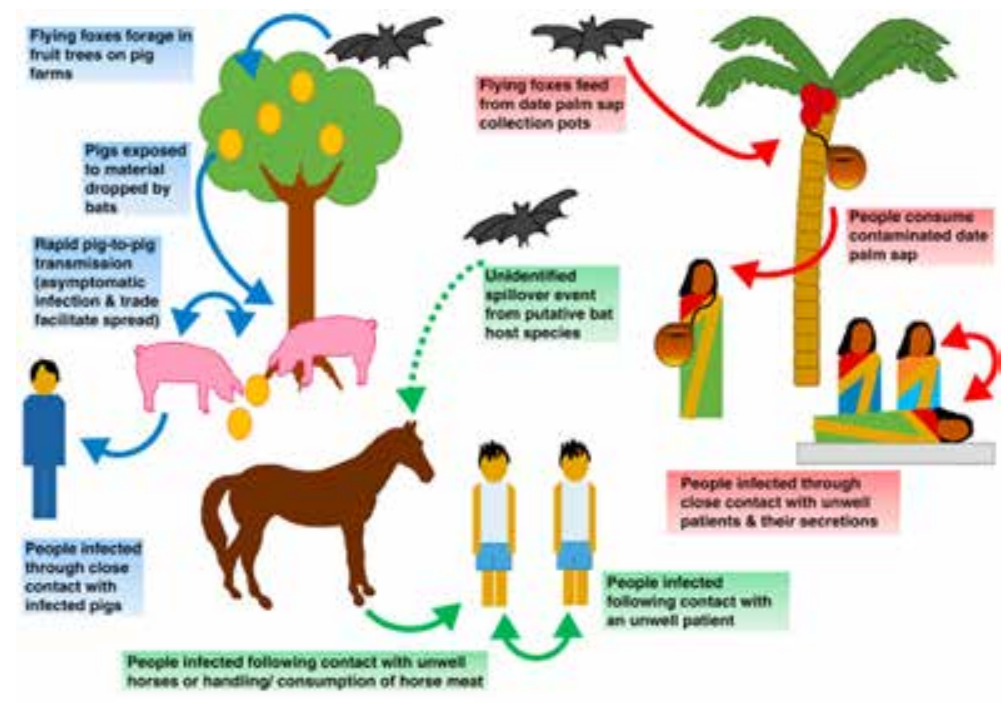

\section{Impact on India}

The contamination and pollution, a creating peril, has killed in every way that matters the lion's share of its abused individ-

uals so far in India. An unprecedented, personality was hurting disease that experts consider a possible torment threat has broken out in the region of Kerala, India, unexpectedly, defiling something like 18 people and killing 17 of them, as shown by the World Health Organization. ${ }^{2}$ There is no sensible preventive or treatment for Nipah, an as of late rising affliction spread by bats, pigs and people who have ended up being corrupted, according to the Centers for Disease Control and Prevention and the World Health Organization. WHO has been instructed about Nipah contamination cases being represented in a family from a town in Kozhikode territory of Kerala,» he said. "Both the central and the state prosperity masters have been smart in responding to the condition and have immediately passed on gatherings and authorities to the town also to overview the situation. WHO is in close contact with the gatherings of pros passed on to the affected zones. We foresee the evaluation reports of the gatherings to explain the condition and guide advance action". ${ }^{3}$ The present scene is suspected of having been spread by polluted natural organic product bats. ${ }^{4}$

Amid January and February of 2001, an episode of febrile ailment with adjusted sensorium was seen in Siliguri, West Bengal, India. Siliguri is a critical business focus with a populace of $\approx 500,000$. It is close outskirts with China, Bangladesh, Nepal, and Sikkim. The flare-up happened among hospitalized patients, family contacts of the patients, and restorative staff of 4 doctor's facilities. Japanese encephalitis, which is endemic around there, was at first suspected. However, the age assembles influenced, and the epidemiologic highlights recommended another infection. Research facility examinations directed at the season of the flare-up neglected to distinguish an irresistible operator. Nipah infection (NiV), an as of late emanant, zoonotic paramyxovirus, was ensnared as the reason for an exceedingly deadly (case-casualty proportion $38 \%-75 \%$ ), febrile human encephalitis in Malaysia and Singapore in 1999 and Bangladesh amid the winters of 2001, 2003, and 2004. The regular repository of $\mathrm{NiV}$ is attempted to be fruit bats of the sort Pteropus. Proof of NiV disease was identified in these bats in Malaysia, Bangladesh, and Cambodia. In the Malaysian flareup, $\mathrm{NiV}$ was brought into the pig populace, and the vast major- ity of the human cases came about because of introduction to sick pigs. In any case, a middle of the road creature has been not distinguished amid the Bangladesh episodes, which recommends that the infection was transmitted either individually or in a roundabout way from contaminated bats to people. $\mathrm{Hu}-$ man-to-human transmission of $\mathrm{NiV}$ was additionally archived amid the episode in Faridpur, Bangladesh. Since the clinical indications of the cases in Siliguri were like those of $\mathrm{NiV}$ cases in Bangladesh, and because Siliguri is close influenced regions in Bangladesh, a review investigation of clinical examples was embraced to decide whether $\mathrm{NiV}$ was related with the Siliguri outbreak. ${ }^{5}$ Not just in India yet additionally influenced in the neighboring nation too is influenced.

$\mathrm{NiV}$ has been set up as the reason for deadly, febrile encephalitis in human patients in Bangladesh amid the winters of 2001, 2003, and 2004. A NiV like the infection was recognized as the reason for the episodes in 2001 and 2003 based on serologic testing. Two flare-ups comprising of 48 instances of $\mathrm{NiV}$ were recognized in 2004 of every 2 adjacent areas (30 km separated) of focal Bangladesh (Rajbari and Faridpur) with a case-casualty rate of almost $75 \%$. Due to high observation, other little groups and confined cases $(n=19)$ were recognized amid a similar period in seven different locales in focal and northwest Bangladesh. Even though antibodies to $\mathrm{NV}$ were recognized in organic product bats from the influenced regions in 2004, a halfway creature have been not distinguished, which recommends that the infection was transmitted from bats to people. Human-to-human transmission of NiV was additionally recorded amid the Faridpur episode. Which depicts the hereditary attributes of $4 \mathrm{NiV}$ secludes from the episode in Bangladesh in 2004. ${ }^{6}$ (table 1)

$$
\text { Table 1: Date, location and number of cases Niv virus. }
$$

\section{Disease in Humans}

$\mathrm{NiV}$ caused genuine, rapidly powerful encephalitis that passed on a high demise rate. In light of the time break between the last introduction to pigs and subsequent start of the malady, the agonizing period stretched out from 4 days to 2 months with more than $90 \%$ 


\begin{tabular}{|c|c|c|c|}
\hline Sri & Date & Restition & Case \\
\hline 1. & $\begin{array}{l}2001 \text { January 31-23 } \\
\text { February. }\end{array}$ & Siliguri. India. & $\begin{array}{l}66 \text { cases with a } 74 \% \text { mortality rate. } 75 \% \text { of } \\
\text { patients were either hospital staff or lad visited } \\
\text { one of the other patients in hospital, indicating } \\
\text { person-to-person transmission. }\end{array}$ \\
\hline 2 & 2001 April - May. & $\begin{array}{l}\text { Meloerpur District, } \\
\text { Bangladesh. }\end{array}$ & 13 cases with nine fatalities ( $69 \%$ mortality). \\
\hline 3. & 2003 Jantury, & $\begin{array}{l}\text { Naogaon District, } \\
\text { Bangladesh. }\end{array}$ & 12 cases with eight fatalities ( $67 \%$ mortality) \\
\hline 4 & 2004 January - February. & $\begin{array}{l}\text { Manikganj and Rajbari } \\
\text { districts. Bangladesh. }\end{array}$ & 42 cases with I 4 fatalities ( $33 \%$ mortality). \\
\hline 5 & $\begin{array}{c}200419 \text { February }-16 \\
\text { April. }\end{array}$ & $\begin{array}{l}\text { Faridpur District. } \\
\text { Bangladesh. }\end{array}$ & $\begin{array}{l}36 \text { cases with } 27 \text { fatalities ( } 75 \% \text { mortality). } 92 \% \\
\text { of cases imvolved close contact with at least one } \\
\text { other person infected with Nipah vints. Two cases } \\
\text { involved a single short exposure to an ill patient. } \\
\text { including a rickshaw driver who transported a } \\
\text { patient to hospital. In addition, at least six cuses } \\
\text { unvolved acute respiratory distress syndrome. } \\
\text { which has not been reported previously for Nipah } \\
\text { virus illness in humans. This symptom is likely to } \\
\text { have assisted buman-to-buman transmission } \\
\text { through large droplet dispersal. }\end{array}$ \\
\hline 6 & 2005 Jagtuary. & $\begin{array}{l}\text { Tangail District, } \\
\text { Bangladesh. }\end{array}$ & $\begin{array}{l}12 \text { cases with } 11 \text { fatalities }(92 \% \text { mortality). The } \\
\text { virus was probably contracted from drinking date } \\
\text { palm juice contaminated by fruit bat droppings or } \\
\text { saliva. }\end{array}$ \\
\hline 7 & 2007 February - May. & Nadia District, India. & $\begin{array}{l}\text { Up to } 50 \text { suspected cases with } 3-5 \text { fatalities. The } \\
\text { outbreak site borders the Bangladesh district of } \\
\text { Kushria where eight cases of Nipah vins } \\
\text { encephalitis with frve fatalities occurred during } \\
\text { March and April } 2007 \text {. An outbreak preceded this } \\
\text { in Thakargaon during January and February } \\
\text { affecting seven people with three deaths. All three } \\
\text { outbreaks showed evidence of person-to-person } \\
\text { transmission. }\end{array}$ \\
\hline 8: & 2008 Febnuary - March. & $\begin{array}{l}\text { Manikganj and Rajbari } \\
\text { districts. Baneladesh. }\end{array}$ & Nine cases with eight fatalities. \\
\hline 9 & 2010 January. & $\begin{array}{l}\text { Bhangra subdistrict. } \\
\text { Faridpur, Bangladesh. }\end{array}$ & $\begin{array}{l}\text { Eight cases with seven fatalities. During March. } \\
\text { one physician of Fanidpur Medical College } \\
\text { Hospital caring for confirmed Nipah cases died. }\end{array}$ \\
\hline 10. & $20114^{\mathrm{a}}$ February. & $\begin{array}{c}\text { Hatibundha, Lalmoairhat. } \\
\text { Bangladesh. }\end{array}$ & $\begin{array}{l}\text { An outbreak of Nipah Virus oscurred at } \\
\text { Hatibandha. Lalmonirhat, Bangladesh. The } \\
\text { deaths of } 21 \text { schoolchildren due to Nipah virus } \\
\text { infection were recorded on } 4 \text { Febriary } 2011 \text {. } \\
\text { IFDCR confimed the infection was due to this } \\
\text { virus. Local schools were closed for one week to } \\
\text { prevent the spread of the vinis. People were also } \\
\text { requested to avoid consumption of uncooked } \\
\text { fnuts and fruit products. Such foods, } \\
\text { contaninated with urine or saliva from infected } \\
\text { fruit bats, were the most likely source of this } \\
\text { outbreak. }\end{array}$ \\
\hline 11 & 2018 May. & Calicut, Kerala, India. & $\begin{array}{l}\text { Deaths of seventeen people in Perambra near } \\
\text { Calicut. Kerala, India were confirmed to be due to } \\
\text { the virus. Treatment using antivirals such as } \\
\text { Ribavirin was initiated. }\end{array}$ \\
\hline
\end{tabular}

of patients giving a past loaded up with around fourteen days or less. In NiV, the rate of subclinical sickness kept running from 8 to $15 \%$. The bigger piece of patients showed symptoms related to the central tactile framework, yet respiratory system commitment was in the like manner seen in various patients in Singapore. Around $40 \%$ of patients gave were ran with respiratory sickness. Over the prior decade, the beforehand dim paramyxoviruses Hendra sullying $(\mathrm{HeV})$ and Nipah infection $(\mathrm{NiV})$ have made in people and subdued animals in Australia and Southeast Asia. The two illnesses are overpowering, exceedingly harming, and arranged for dirtying diverse mammalian species and causing possibly destructive infirmity. ${ }^{7}$ Because of the nonattendance of an endorsed checking operator or antiviral drugs, $\mathrm{HeV}$ and $\mathrm{NiV}$ are doled out as biosafety level (BSL) four experts and are potential bioterrorist overseers. The genomic structure of the two defilements is that of a run of the mill paramyxovirus. In any case, by constrained movement homology and immaterial immunological cross-reactivity with different paramyxoviruses, $\mathrm{HeV}$ and $\mathrm{NiV}$ have been depicted into another variety inside the family Paramyxoviridae named Henipavirus. The clinical signs were fever, cerebral torment, dazedness, and hurling. More than $50 \%$ of the patients had a diminished dimension of mindfulness and recognizable cerebrum stem brokenness. Progressively settled patients, especially those having diabetes mellitus and those with genuine cerebrum stem commitment passed on a poorer expectation. The signs found in patients amid Siliguri erupt fever, headache, and myalgia, spewing, balanced sensorium, respiratory signs (tachypnea to extraordinary respiratory inconvenience) and programmed advancements or fits. Patients were normotensive at affirmation yet wound up hypertensive before death. The case loss in clinical cases was around $40 \%$ in the Malaysian scenes in Bangladesh and India, and it was on a typical $75 \% .^{8}$ The partition of another paramyxovirus, as such named Nipah disease, from cerebrospinal fluid precedents from a couple of patients demonstrated this was the etiologic authority. Starter examinations of nucleotide sequencing revealed that this contamination is solidly related to, not unclear to, Hendra disease, which caused ailment among steeds and affected three patients in Australia. ${ }^{9}$ Nipah disease is most immovably related to Hendra contamination, which was first seen in Australia in 1994 amid a respiratory sickness scene among horses and individuals. Normal examinations of next Australian untamed life entangled 
natural organic product bats of the family Pteropus as the first animal supply for Hendra disease. Despite two occurrences of an extraordinary respiratory ailment, Hendra disease caused a case of deadly encephalitis. Hendra contamination transmission in all likelihood results from contact with body fluids, including pee, from corrupted animals. However, most paramyxoviruses are species specific, Hendra and Nipah diseases are fit for sullying an arrangement of vertebrates. In 10 March through 19 March 1999, 11 occurrences of febrile encephalitis or pneumonia that realized one passing occurred among pros at 1 of 2 abattoirs in Singapore. Simply outside made pigs were set up in the abattoirs; $82 \%$ started from Malaysia. Serologic or viral imprisonment inspects included Nipah disease tainting in every one of the 11 patients. ${ }^{10}$

\section{Respiratory Infection}

The respiratory epithelium is a basic first line of boundary and viably connected with exacerbation and host opposition against powerful diseases. In human cases of $\mathrm{NiV}$ ailment, $\mathrm{NiV}$ can be perceived in bronchiolar epithelial cells and is shed generally by nasopharyngeal and tracheal releases in the early time of the infection. Patients with symptomatic respiratory tract defilements were out and out increasingly slanted to transmit NiV. Histological changes in the lungs of $\mathrm{NiV}$ cases fuse necrotizing alveolitis with depleting, aspiratory edema, and want pneumonia. Multinucleated mammoth cells are now and again noted in the alveolar septum and alveolar spaces close-by necrotic zones. Intra-alveolar red hot cells are ordinary. The important deadly human occasion of $\mathrm{HeV}$ tainting realized outrageous respiratory disease in which the lungs had net wounds of stop up deplete and edema related with steady histological alveolitis. For the most part, histopathological changes in tracheal/bronchial epithelium were remarkable. In exploratory animal models, viral antigen is at first discernible in the bronchi and alveoli, generally concentrating on the bronchial epithelium and type II pneumocytes. We are starting late exhibited that HNV can capably corrupt epithelial cells from the lower human respiratory tract and rehash to high titers. While human-to-human transmission has been observed just in flare-ups with NiV-B, these data prescribe that both $\mathrm{NiV}$ and $\mathrm{HeV}$ have the potential for human-to-human transmission through pressurized canned items. HNV sullying of the respiratory epithelium results in the acknowledgment of red hot cytokines which result in the selection of immune cells and can progress to an Acute Respiratory Distress Syndrome (ARDS) - like affliction. Infection of the lower respiratory tract epithelium results in a combustible differential response depending upon the goals of defilement. HNV tainting of the little avionics course epithelium realized enrollment of key provocative go-betweens, for instance, IL-6, 8, IL-1 $\alpha$, MCP-1, G-CSF, GM-CSF, and CXCL10. Strikingly, red hot cytokine enunciation was out and out lower in trachea/ bronchial epithelium. This recognition is in simultaneousness with past reports that no exacerbation is found in the bronchial epithelium of NiV cases. An impressive part of these key cytokines in HNV defilement accept a vocation in ARDS and are in like manner exceedingly imparted during illness with other unsafe respiratory contaminations, for instance, $\mathrm{H} 5 \mathrm{~N} 1$ and SARS-CoV. During the late periods of affliction, contamination replication spreads from the respiratory epithelium to the endothelium in the lungs. The malady can occur on occasion trigger a prominent vasculitis in little vessels and vessels as depicted by endothelial syncytium and divider painting rot. Broad vessels are typically not impacted. HNV would then have the capacity to enter the circulatory framework and dissipate all through the host fit as a fiddle or by limiting host leukocytes. Despite the lungs, vital target organs are the brain, spleen, and kidneys, and viremia following respiratory illness can incite multi-organ disappointment. ${ }^{11}$

\section{Entry in The CNS}

HNV disease of the CNS and the advancement of neurological signs are related with the disturbance of the blood-mind boundary (BBB) and articulation of TNF $\alpha$ and IL-1 $\beta$. These expert fiery cytokines have been appeared to assume a job in expanding the porousness of the blood-cerebrum hindrance just as the enlistment of neuronal damage and demise. While the wellspring of TNF- $\alpha$ and IL- $1 \beta$ articulation in the cerebrum is as of now obscure, they can be discharged by microglia, which are additionally tainted by HNV. In any case, regardless of whether disturbance of the BBB is a direct cytopathic impact of infection replication in the microvasculature or an aberrant impact through the articulation of TNF- $\alpha$ and IL-1 $\beta$ by onlooker cells, for example, neurons and microglia stay misty. Exploratory examinations in different creature models have demonstrated right section of the CNS by HNV, through the olfactory nerve. In these models, NiV contaminates the olfactory epithelium in the nasal turbinates. $\mathrm{NiV}$ along these lines taints neurons stretching out through the cribriform plate into the olfactory knob, giving a next course section into the CNS. NiV then scatters to the olfactory tubercle and all through the ventral cortex. It is at present obscure whether this course is likewise naturally applicable in human diseases since the olfactory epithelial surface is generally substantial in these species contrasted with the man. ${ }^{11}$

\section{Disinfection}

Like distinctive paramyxoviruses, Nipah contamination is speedily inactivated by chemicals, chemicals, and various disinfectants. Routine cleaning and filtration with sodium hypochlorite or financially open disinfectants are required to propel. Sodium hypochlorite was endorsed for the filtration of pig develops in Malaysia. The effect of warmth may depend upon the substrate. Nipah contamination centers decreased yet the disease was not completely discarded in phony palm sap held at $70^{\circ} \mathrm{C}$ for an hour. In any case, it was completely inactivated by warming at $100^{\circ} \mathrm{C}$ for over 15 minutes. ${ }^{12}$

\section{Current treatment procedures}

Treatment is restricted to strong consideration. The medication ribavirin has been appeared to be viable against the infections in vitro, yet human examinations to date have been uncertain, and the clinical convenience of ribavirin stays unverifiable. Nipah infection contamination can be anticipated by keeping away from an introduction to wiped out pigs and bats in endemic territories and not drinking raw date palm sap. ${ }^{13}$ However, for good countermeasures and readiness, a more extensive and increasingly far-reaching approach and venture are earnestly required. Notwithstanding diagnostics, therapeutics, and antibodies, observation foundation must be enhanced to distinguish and check cases quickly, lead point by point contact following, research overflows, and better comprehend the environment of bats and Nipah infection disease, particularly outside of flare-up situations. As essential is the requirement for social change: nearby networks must be better upheld to guarantee disease avoidance and control measures in wellbeing offices to decrease transmission and to direct the network commitment and training required to alter conduct and lessen hazard. We should notice that Nipah infection requests an expansive, long haul procedure and pandemic arrangement. ${ }^{14}$

Oral administration of favipiravir completely shields from deadly Nipah infection disease in the hamster demonstrate. Favipiravir has been exhibited to diminish mortality in different exploratory models of viral hemorrhagic fever, encephalitis, or respiratory malady. To assess the in vivo viability of favipiravir against NiV-M, we used the Syrian hamster display which intently 
reflects most parts of human ailment, for example, far-reaching vasculitis, pneumonia, and encephalitis and has been generally acknowledged for the assessment of antiviral therapeutics and antibody hopefuls. Hamsters were tainted with a terminal portion of 104 PFU NiV-M using the intraperitoneal (i.p.) course like past examinations and treatment was started following contamination. Favipiravir was controlled twice every day utilizing the perioral (p.o.) course for 14 days, again like past investigations assessing the antiviral action of favipiravir. On test day, a stacking portion of $600 \mathrm{mg} / \mathrm{kg} / \mathrm{d}$ was directed following disease, trailed by $300 \mathrm{mg} / \mathrm{kg} / \mathrm{d}$ on days $1-13$.

A similar timetable with vehicle dosed control creatures as it were. All vehicle-treated NiV-tainted creatures consistently created clinical indications of sickness including hyperreflexia, ataxia, irregular breathing, and dormancy and surrendered to malady or were others consciously euthanized on days 5 or 6 PI. Creatures treated with favipiravir did not create clinical indications of sickness throughout the investigation through 42 days of post disease. Besides, weight information uncovered soak weight reduction before death or killing in vehicle-treated creatures, while favipiravir-treated creatures consistently put on load all through the length of the examination. Infection titrations from tissues were uncertain as we were just ready to recoup possible infection in one of the four vehicle-treated creatures, yet no infection was identified in the favipiravir-treated gathering (information not appeared). Constant RT-PCR for the viral P quality was directed on minds, spleens, and lungs to think about viral load between deadly creatures that were euthanized and survivors. Not surprisingly, large amounts of viral P quality articulation were recognized in each of the three tissues in the vehicle-just controls contrasted with favipiravir-treated creatures, where no popular RNA was distinguished. Two of five survivors created killing neutralizer titers (PRNT50s) of $>80$ and $>1280$, separately, while the staying three survivors had titers of $<20$. These outcomes show that favipiravir regulated twice day by day p.o. starting following disease is very strong in forestalling $\mathrm{NiV}$-instigated grimness and mortality in the hamster demonstrate.

Association of favipiravir subcutaneously shields hamsters from destructive Nipah disease defilement. To choose the sufficiency of once to step by step subcutaneous (s.c.) association of favipiravir, for instance, starting late used in a Lassa disease (LASV) guinea pig model33, hamsters were polluted with a fatal segment of 104 PFU NiV-M through the i.p. course and treatment were begun rapidly after infection. Like the oral association think about portrayed more than, a stacking bit of $600 \mathrm{mg} / \mathrm{kg} / \mathrm{d}$ was controlled rapidly after pollution, trailed by $300 \mathrm{mg} / \mathrm{kg} / \mathrm{d}$ on days $1-13$. All vehicle-treated animals ended up being wiped out inside 7 DPI and demonstrated signs of loss of movement, ataxia, and sporadic unwinding. Favipiravir-treated animals made due until the completion of the examination (42 DPI) with no enhancement of clinical signs of ailment and reliably put on load over the range of the examination. Correspondingly similarly as with the past examination, attempts at disease titration from tissue were dubious, and RT-PCR recognized high stores of the viral $\mathrm{P}$ quality in every one of the three tissues assessed in non-treated animals, while the viral load in all survivors was not noticeable. Of the five enduring animals, three made slaughtering insusceptible reaction titers (two $>80$ and one $>20$ ), while the remaining two survivors had titers of $<20$. These results demonstrate that association of favipiravir s.c. At the point when step by step beginning right away after the illness is furthermore significantly satisfactory in maintaining a strategic distance from NiV-actuated frightfulness and mortality in the hamster model. ${ }^{15}$ Virus partition is required for finish assurance; managing NiV requires a BSL4 investigate office. Led the Swine Health Information Center by the Center for Food Safety and Public Health, School of
Veterinary Medicine, Iowa State University in September 2015. Quantitative consistent polymerase chain reaction (qRT-PCR) is open, as is immunohistochemistry. Immunofluorescence may be confounded by cross-reactivity with Hendra contamination, though a couple of monoclonal antibodies are as of now available for henipavirus detachment. An underhanded protein associated immunosorbent look at (ELISA), contamination balance tests using pseudotype particles, and multiplexed microsphere measures have all been delivered to perceive antibodies to NiV at the BSL2 level. ${ }^{16}$ Another methodology which is encountering is upon Fusion Glycoprotein system.

The paramyxoviruses include a social event of major human pathogens, for instance, measles, mumps, human parainfluenza diseases, and the significantly pathogenic Nipah (NiV) and Hendra $(\mathrm{HeV})$ contaminations. $\mathrm{NiV}$ defilements have a demise rate in individuals of up to $75 \%$, and $\mathrm{NiV}$ is named a BSL4 pathogen because of its profile oragro-mental fighting potential. The suitability of segment inhibitors centered against HIV suggests that a prevalent cognizance of Paramyxovirus entry and blend will energize similarly strong antiviral therapeutics. ${ }^{17}$

Figure 2. Nipah virus (NiV) is a member of the family Paramyxoviridae, genus Henipavirus. Henipaviruses are pleiomorphic with spherical or filamentous structures ranging from 40 to $2000 \mathrm{~nm}$ in size. Nucleocapsids are visible in electron microscopy with a diameter of about $18 \mathrm{~nm}$. 19 (ID 117970591 @ Katerynakon | Dreamstime.com)

\section{Conclusion}

For good countermeasures and readiness, a more extensive and more far-reaching approach and venture are critically required. Notwithstanding diagnostics, therapeutics, and antibodies, reconnaissance foundation must be enhanced to recognize and confirm cases quickly, direct point by point contact following, research overflows, and better comprehend the environment of bats and Nipah infection contamination, particularly outside of flare-up situations. As vital is the requirement for social change: nearby networks must be better upheld to guarantee disease anticipation and control measures in wellbeing offices to diminish transmission, and to lead the network commitment and instruction required to alter conduct and decrease chance. We should notice that Nipah infection requests an expansive, long haul sys-

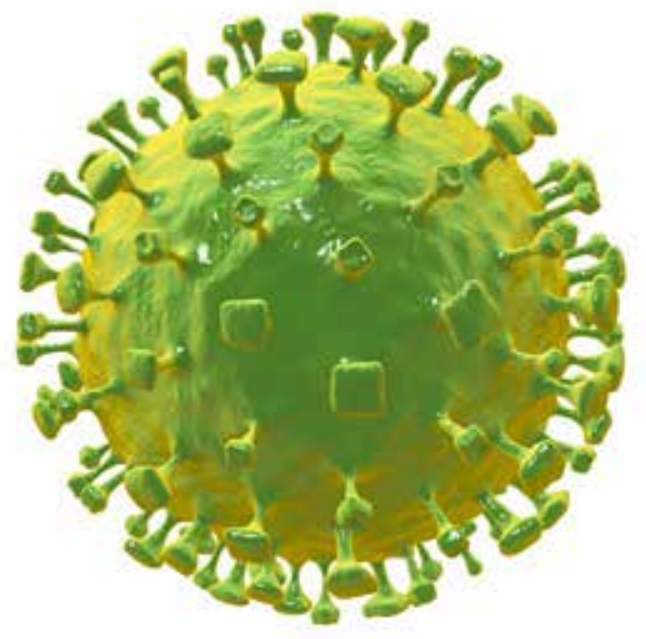

tem and pandemic arrangement. Favipiravir treatment results in diminished viral antigen and histopathological changes. With the end goal to decide the neurotic changes present in favipira- 
vir-treated NiV-M-contaminated hamsters, we inspected cerebrum, spleen, and lung gathered from euthanized creatures amid the examination and survivors at 42 DPI utilizing H\&E stains and IHC against NiV nucleoprotein. Vehicle-treated creatures showed trademark obsessive sores of $\mathrm{NiV}$ disease: Lungs showed perivascular penetration of provocative cells, and $\mathrm{NiV}$ antigens were recognized in endothelial cells, which infrequently shaped syncytia, and also in smooth muscle cells of pneumonic vessels. Gentle to direct interstitial pneumonia with alveolar edema or drain and intermittent increment in sort II pneumocytes were likewise observed. In the spleen, follicles were less unmistakable, and the red mash string showed necrotic territories scattered with mononuclear or reticular cells with $\mathrm{NiV}$ antigens. In cerebrums, meningitis with a penetration of neutrophils and mononuclear cells was found, and viral antigens were identified in mononuclear cells with lengthened cytoplasm in meninges and every so often in neurons in the parenchyma. Tissues of creatures which were treated with favipiravir, either p.o. or on the other hand s.c., were comparative: no remarkable discoveries of sicknesses were distinguished in minds, lungs, and spleens in the H\&E areas. None of the treated hamsters showed perceptible NiV antigens in cerebrums, lungs, or spleen spleens. Lungs of treated hamsters did not demonstrate cell penetration in pneumonic veins, albeit gentle union of lung parenchyma was watched.

\section{Acknowledgment}

I gratefully acknowledge the encouragement and support extended by Dr. Biplab Debnath Sir for his real guidance during the investigations and of course for his motivation. I sincerely thank my parents for moral support and for the economic help.

\section{References}

1. Centers for Disease Control and Prevention. Outbreak of Hendra-like virus-Malaysia and Singapore, 1998-1999. MMWR Morb MortalWkly Rep. 1999;48:265-9.

2. Nipah Virus, Rare and Dangerous, Spreads in India - www.nytimes. com/2018/06/04/health/nipah-virus-india-vaccine-epidemic.html

3. Nipah: Kerala Lifts High Alert, Schools to Reopen on June12 -www. india.com/news/india/nipah-kerala-lifts-high-alert-schools-to-reopen-on-june-12-3102631//

4. Rare, Brain-Damaging Virus Spreads Panic In India As Death Toll Rises - www.washingtonpost.com/news/to-your-health/ wp/2018/05/22/rare-brain-damaging-virus-spreads-panic-in-indiaas-death-toll-rises/?noredirect $=$ on\&utm_term $=.55851 \mathrm{a}$ aff607

5. Chadha Mandeep S., Comer James A., Lowe Luis, Rota Paul A., Rollin Pierre E., Bellini William J., Ksiazek Thomas G., Mishra Akhilesh C.. Nipah Virus-associated Encephalitis Outbreak, Siliguri, India. Emerging Infectious Diseases. 2006;12(2):235 - 240.

6. Harcourt Brian H., Lowe Luis, Tamin Azaibi, Liu Xin, Bankamp Bettina, Bowden Nadine, Rollin Pierre E., Comer James A., Ksiazek Thomas G., Hossain Mohammed Jahangir, Gurley Emily S., Breiman Robert F., Bellini William J., Rota Paul A.. Genetic Characterization of Nipah Virus, Bangladesh- 2004. Emerging Infectious Diseases. 2005; 11(10):1594 - 1597.

7. Henipah Virus Details - Wiki - https://en.wikipedia.org/wiki/Henipavirus .

8. Kulkarni D.D, Tosh C., Venkatesh G., Kumar D. Senthil. Nipah Virus Infection: Current Scenario. 2013; 24(3):398-408.

9. Goh Khean Jin, Tan Chong Tin, Chew Nee Kong, Tan Patrick Seow Koon, Kamarulzaman Adeeba, Sarji Sazilah Ahmad, Wong Kum Thong, Abdullah Basri Johan Jeet, Chua Kaw Bing, Lam Sai Kit, Clinical Features Of Nipah Virus Encephalitis Among Pig Farmers In Malaysia. The New England Journal of Medicine. 2000; 342(17):1229 - 1235.

10. Chew Madeleine H. L., Arguin Paul M., Shay David K., Goh Kee-Tai,
Rollin Pierre E., Shieh Wun-Ju, Zaki Sherif R., Rota Paul A., Ling AiEe, Ksiazek Thomas G., Chew Suok-Kai, Anderson Larry J.. Risk Factors for Nipah Virus Infection among Abattoir Workers in Singapore. The Journal of Infectious Diseases. 2000; 181:1760-1763.

11. Olivier Escaffre, Viktoriya Borisevich, Barry Rockx. Pathogenesis of Hendra and Nipah virus infection in humans. J Infect Dev Ctries. 2013; 7(4): 308 - 311.

12. Article - Nipah Virus Infection - Nipah Virus Encephalitis, Porcine Respiratory and Encephalitis Syndrome, Porcine Respiratory and Neurologic Syndrome, Barking Pig Syndrome. 2016;1 - 9.

13. CDC - National Center for Emerging and Zoonotic Infectious Diseases - Nipah Virus (NiV).

14. World Report Lancelet. 2018; $391: 2295$

15. Dawes Brian E., Kalveram Birte, Ikegami Tetsuro, Juelich Terry, Smith Jennifer K., Zhang Lihong, Park Arnold, Lee Benhur, Komeno Takashi, Furuta Yousuke, Freiberg Alexander N.. Favipiravir (T-705) Protects Against Nipah Virus Infection In The Hamster Model. Scientific Reports. 2018; 8(7604):1 - 11.

16. Article - Nipah Virus - Prepared for the Swine Health Information Center By the Center for Food Security and Public Health. College of Veterinary Medicine. Iowa State University September 2015.

17. Aguilar Hector C., Ataman ZeynepAkyol, SpericuetaVanessa A., Fang Angela Q., Stroud Matthew, Negrete OscarA., Kammerer RichardA., Lee Benhur. A Novel Receptor-induced Activation Site in the NipahVirus Attachment Glycoprotein $(G)$ Involved in Triggering the Fusion Glycoprotein(F). Journal of biological chemistry. 2009; 284(3) :1628 - 1635 .

18. Fogarty, R., Halpin, K., Hyatt, A. D., Daszak, P., \& Mungall, B. A. (2008). Henipavirus susceptibility to environmental variables. Virus Research, 132(1-2), 140-144.doi:10.1016/j.virusres.2007.11.010

Received: 14 January 2019

Approved: 28 February 2019 